\title{
Extraction of Pectin from Ripe Plantain Peel, Fabrication and Characterization of Composite (Pectin/PVA/Glycerol) Films Produced from the Extracted Pectin
}

\author{
Chizoba May Obele ${ }^{1}$, Stanley Udochukwu Ofoegbu², Chioma Irene Awuzie ${ }^{3}$ \\ ${ }^{1}$ Department of Polymer and Textile Engineering, Nnamdi Azikiwe University, Awka, Nigeria \\ ${ }^{2}$ Department of Materials and Ceramic Engineering, CICECO-Aveiro Institute of Materials, University of Aveiro, Campus \\ Universitário de Santiago, Aveiro, Portugal \\ ${ }^{3}$ Department of Science Laboratory Technology, Federal Polytechnic, Oko, Nigeria \\ Email: angelobele1@yahoo.co.uk
}

How to cite this paper: Obele, C.M., Ofoegbu, S.U. and Awuzie, C.I. (2019) Extraction of Pectin from Ripe Plantain Peel, Fabrication and Characterization of Composite (Pectin/PVA/Glycerol) Films Produced from the Extracted Pectin. Journal of Minerals and Materials Characterization and Engineering, 7, 454-467.

https://doi.org/10.4236/jmmce.2019.76032

Received: June 3, 2019

Accepted: November 24, 2019

Published: November 27, 2019

Copyright ( 2019 by author(s) and Scientific Research Publishing Inc. This work is licensed under the Creative Commons Attribution International License (CC BY 4.0).

http://creativecommons.org/licenses/by/4.0/

\begin{abstract}
High methoxyl pectin $(\mathrm{DE}=59.53 \%)$ was extracted from plantain peel using acid extraction method. Pectin yield was 40.5\%; moisture content was 87.56\%; equivalent weight was $1000 \mathrm{~g} / \mathrm{ml}$, and galacturonic acid content was $2.89 \mathrm{mg} / \mathrm{ml}$. Composite polymer films incorporating the extracted pectin manifest their best mechanical properties; tensile strength and \% elongation of $5.51 \mathrm{MPa}$ and $5.75 \%$ respectively with $10 \mathrm{ml}$ glycerol/1g pectin. Raman spectra peaks at $2930 \mathrm{~cm}^{1}, 1750 \mathrm{~cm}^{-1}$ and $820 \mathrm{~cm}^{-1}$ indicated $\mathrm{CH}$-stretch, $\mathrm{C}=\mathrm{O}$ ester group of pectin and $\mathrm{COH}$ ring in pectin respectively. Films containing pectin sourced from waste are considered potential alternative sources of environmentally benign packaging materials.
\end{abstract}

\section{Keywords}

Composite Films, Waste, Bio Economy, Sustainable, Raw Materials

\section{Introduction}

Pectin is an excellent carbohydrate polymer derived from mainly natural resources and is the structural component of plant cell wall [1]. Chemically, pectin is poly $\alpha$-1, 4-galacturonic acid, with varying degree of methylation of carboxylic acid residues. Pectin with more than $50 \%$ methyl ester groups is classified as high-methoxyl (HM) and those with less than 50\% methyl ester groups as low-methoxyl (LM). The degree of esterification of galacturonic acid residues of 
pectin is the most important parameter which affects the solubility of pectin and its gelling and film forming properties. Pectin has been extracted from a wide variety of agricultural products/waste such as citrus peel/waste [2]-[7], mango peel/waste [8] [9] [10] [11] [12], plant leaves [13] [14] [15], banana peels [16] [17] [18] [19] [20], and plantain peel [21]. To the best of our knowledge, there has been only a few reports on the extraction of pectin from plantain peel [22] [23]. Reference [21] studied the effects of the ripeness stage of banana (Musa $\mathrm{AAA}$ ) and plantain (Musa AAB) peels on pectin contents, and pectin chemical features among other constituents and reported higher pectin content in banana peels compared to plantain peels at all the stages of maturation, with the average molecular weights of the extracted pectin in the range of $132.6-573.8 \mathrm{kDa}$ and that whilst acid extraction was the most efficient for isolating pectin from banana peel, and an ammonium oxalate extraction was more adequate for plantain peels. A comparison of the characteristics of pectin extracted from different fruit wastes has been reported [23] as well as a comprehensive review of pectin, its uses and sources [24]. Recently, there has been a growing interest in the development and exploitation of bio-based materials derived from agricultural resources with increasing interest in the concept of a bio-economy in which the utilisation/re-utilisation of biogenic waste is vital [25]-[30].

Indeed, edible films and coatings can be used as a vehicle for incorporating natural or chemical antimicrobial agents, antioxidants, enzymes or functional ingredients such as probiotics, minerals and vitamins. Pectin based films has been produced by several authors [31] [32]. Chitosan/pectin films with either glycerol or lactic as plasticizer to give clear laminated films with dynamic mechanical properties similar to those for pectin films alone had been fabricated [33] and thermal analysis of pectin had been carried out [34]. This study reports acid extraction of pectin from plantain peel and the development of edible film from plantain pectin. Quantitative tests such as degree of esterification, total galacturonic acid content, Raman intensity measurements and differential thermal analysis were carried out on the extracted pectin. Mechanical tests, such as tensile test, and elongation (ductility) tests, were carried out on the prepared edible films.

\section{Experimental}

\subsection{Materials}

Ripe plantain peel was sourced from food vendors around Nnamdi Azikiwe University, Awka, Nigeria. Analytical grade hydrochloric acid, glycerol, isopropyl alcohol, Poly (vinyl alcohol) from Sigma Aldrich (of $M_{w} 89,000$ - 98,000) were used as received. Citrus pectin sourced from Sigma Aldrich was used to compare the properties of the pectin produced from plantain peel in this study.

\subsection{Methods}

\section{Acid extraction of pectin.}


The ripe plantain peel was thoroughly washed, cut into pieces and then ground with corona manual grinder. Care was taken during grinding to get particle size with sufficient surface area to increase extraction using the acid extraction method. Acidified water utilized was prepared by adding $5 \mathrm{~mL} \mathrm{HCl}$ to 1000 $\mathrm{mL}$ of distilled water. $200 \mathrm{~g}$ of the ground ripe plantain peel sample was transferred into a beaker and $250 \mathrm{~mL}$ of acidified water was poured into it and the mixture heated for 30 minutes at $40^{\circ} \mathrm{C}$ using an electric cooker. After the heating procedure, the heated sample was filtered and the extracted pectin was precipitated by adding $250 \mathrm{~mL}$ of $95 \%$ isopropyl alcohol to $100 \mathrm{~mL}$ of extract. The mixture was thoroughly stirred and left to stand for 30 minutes. The gelatinous pectin flocculants were then skimmed off and filtered. It was then purified by washing with hexane to remove residual $\mathrm{HCl}$ and universal salt. The resulting pectin was then characterized and the remaining sample dried in an oven at $30^{\circ} \mathrm{C}$.

\section{Characterization of Pectin}

After acid extraction, pectin is obtained in wet form. A portion of this "wet pectin" sample was dried in an oven at $30^{\circ} \mathrm{C}$ to obtain dry pectin which was stored for future use. The extracted pectin obtained was subjected to qualitative and quantitative test. The following physico-chemical tests were carried out on extracted pectin; colour, solubility in hot and cold water, solubility of wet pectin in cold and hot water, solubility of dry pectin in hot and cold alkali, solubility of dry pectin in cold and hot $\mathrm{HCl}$ and $\mathrm{pH}$ determination. The quantitative tests performed are percentage yield, equivalent weight determination, moisture content determination, degree of esterification and total galacturonic acid content. The Raman spectra of pectin were taken in the range of $50-4000 \mathrm{~cm}^{-1}$ using a Bruker RFS100/S FT-Raman spectrometer wih YAG:Nd laser (1064 nm) excitation source. The TGA/DSC tests were carried out with a Seteram Labsys TG/DSC-16 thermal analysis system.

Pectin yield (wet basis) was evaluated using Equation (1).

$$
\begin{gathered}
\text { Yield of pectin }(\text { wet basis })=\frac{\text { extracted pectin }}{\text { initial amount of ground plantain }} \times 100 \\
\text { Ypectin }(\%)=Y=\frac{100 P}{B_{i}}
\end{gathered}
$$

where, $\mathrm{Ypec}=$ the extracted plantain pectin yield in percent $(\%)$

$P=$ the amount of extracted pectin in $\mathrm{g}$

$B_{i}=$ initial amount of ground plantain peel.

The yield is calculated with respect to the original mass of plantain peel.

The procedures employed in determining the solubility of pectin in different media are given below;

1) Solubility of dry pectin in cold and hot water.

$10 \mathrm{~mL}$ of ethanol was added to $0.15 \mathrm{~g}$ of pectin followed by $50 \mathrm{~mL}$ of distilled water. The mixture was shaken vigorously and the suspension formed was 
warmed at $60^{\circ} \mathrm{C}-70^{\circ} \mathrm{C}$ for 10 minutes.

2) Solubility of wet pectin in cold and hot water.

$50 \mathrm{~mL}$ of distilled water was added to $0.1 \mathrm{~g}$ of pectin and shaken vigorously. The mixture was warmed at $70^{\circ} \mathrm{C}$ for 10 minutes.

3) Solubility of dry pectin in hot and cold alkali $(\mathrm{NaOH})$

$5 \mathrm{~mL}$ of $0.1 \mathrm{~N} \mathrm{NaOH}$ was added to $0.15 \mathrm{~g}$ of pectin and mixture was shaken vigorously. Thereafter, the mixture was warmed at $60^{\circ} \mathrm{C}-70^{\circ} \mathrm{C}$ for 15 minutes. The same process was carried out for wet pectin sample.

4) Solubility of dry pectin in cold and hot $\mathrm{HCl}$

$5 \mathrm{~mL}$ of $0.1 \mathrm{M} \mathrm{HCl}$ was added to $0.1 \mathrm{~g}$ of pectin sample and shaken vigorously and thereafter warmed at $80^{\circ} \mathrm{C}-90^{\circ} \mathrm{C}$. The same process was repeated for $0.2 \mathrm{M}$ $\mathrm{HCl}$.

To determine the moisture contents for plantain peel and for pectin the following procedure was employed. An empty petri dish was dried in an oven and allowed to cool under room temperature then weighed. Next, $5 \mathrm{~g}$ of wet pectin was added to the petri dish and weighed again before being transferred into the oven with temperature set at $100^{\circ} \mathrm{C}$ for 20 minutes. Thereafter, the petri dish was removed, allowed to cool under room temperature and weighed. This process was repeated once and the moisture content was calculated using the Equation (3).

$$
\text { Moisture content }(\%)=\frac{\text { Weight of residue }}{\text { weight of sample }} \times 100
$$

The equivalent weight of pectin was evaluated using the procedure described below and employing Equation (4). Pectin sample of $0.1 \mathrm{~g}$ was weighed into a conical flask and moistened with $5 \mathrm{ml}$ of ethanol. $1.0 \mathrm{~g}$ of sodium chloride was added to the mixture followed by $100 \mathrm{~mL}$ of distilled water and few drops of phenol red indicator and then warmed in a water bath at $75^{\circ} \mathrm{C}$ for 30 minutes. The solution was then slowly titrated with $0.1 \mathrm{M} \mathrm{NaOH}$ to a pink colour at the endpoint.

Equivalent weight was calculated using the Equation (4)

$$
\text { Equivalent weight }=\frac{\text { Weight of pectin } \times 1000}{\text { Volume of alkali } \times \text { Molarity }}
$$

The galacturonic acid content was evaluated by spectrometric methods by measuring the absorbance of pectin containing solutions at $488 \mathrm{~nm}$ against blank solutions. About $1 \mathrm{~g}$ of wet pectin was dissolved in $100 \mathrm{ml}$ of distilled water. From this, $1 \mathrm{~mL}$ was used for sugar analysis. To estimate the polysaccharide content of ripe plantain peel pectin, $1 \mathrm{ml}$ of $5 \%$ phenol was added to the $1 \mathrm{~mL}$ of pectin solution, followed by $5 \mathrm{ml}$ of concentrated sulphuric acid. The absorbance was measured after 10 minutes at $488 \mathrm{~nm}$ against blank. The experiment was carried out in triplicate (Test-1, Test-2, and Test-3) and the average taken. From these values measured at known galacturonic acid content a calibration curve was obtained.

Preparation of standard solution for determination 
A stock solution of $1 \mathrm{~g} / \mathrm{mL}$ of glucose was prepared in $100 \mathrm{~mL}$ of distilled water. Aliquots were taken from this solution to obtain sugar concentrations 1 - 3 $\mathrm{g} / \mathrm{mL}$. $1 \mathrm{~mL}$ of $5 \%$ phenol solution was added to $1 \mathrm{~mL}$ of sugar solution followed by $5 \mathrm{~mL}$ of concentrated sulphuric acid. The absorbance was measured after 10 minutes at $488 \mathrm{~nm}$ against blank.

From the standard galacturonic acid content curve, $y=0.076 x+0.088$ where $y=$ absorbance of pectin sample.

$X=$ galacturonic acid content.

Absorbance of pectin sample $=0.308$

$0.308=0.76 x+0.088$

$$
X=\text { Galacturonic acid content }=\frac{0.22}{0.076}
$$

The degree of esterification (DE) was determined using the procedure described below and Equation (6). $1 \mathrm{~g}$ of pectin was stirred in a mixture of $1 \mathrm{~mL}$ of $2.7 \mathrm{M} \mathrm{HCl}$ and $20 \mathrm{~mL}$ of ethanol $(60 \%(\mathrm{v} / \mathrm{v}))$ for 10 minutes and filtered through a WhatMan filter paper in a funnel. The collected pectin was washed six times with $15 \mathrm{ml}$ of $\mathrm{HCl}$ ethanol mixture, then washed with $60(\mathrm{v} / \mathrm{v}) \%$ ethanol solutions until the filtrate gave a negative response for chloride ions with silver nitrate, and finally washed with $20 \mathrm{~mL}$ ethanol and dried at $105^{\circ} \mathrm{C}$. This treatment removed free sugars and salts, and converted the pectin to the free acid form. The degree of esterification (DE) of pectin was determined by the titrimetric method according to the Food Chemical Codex [35] with a slight modification. Briefly, the dried pectin sample $(100 \mathrm{mg})$ was transferred to a $50 \mathrm{~mL}$ flask, moistened with $2 \mathrm{~mL}$ of ethanol and dissolved in $100 \mathrm{~mL}$ of carbon dioxide-free water. The solution was titrated with $0.1 \mathrm{M} \mathrm{NaOH}$ in the presence of five drops of phenolphthalein indicator and the result was recorded as the initial titer. Then, $20 \mathrm{ml}$ of $0.5 \mathrm{M} \mathrm{NaOH}$ was added under stirring and the mixture allowed to stand for $15 \mathrm{minutes}$ to de-esterify the pectin before $20 \mathrm{ml}$ of $0.5 \mathrm{M} \mathrm{HCl}$ was added, followed by shaking until the pink colour disappeared.

Three drops of phenolphthalein were added and the solution was titrated with $0.1 \mathrm{M} \mathrm{NaOH}$ to a faint pink colour that persisted after vigorous shaking (end point). This titration volume was recorded as the saponification titer (the final titer). The DE was then calculated as follows:

$$
\operatorname{DE}(\%)=\frac{\text { Final titre } \times 100}{\text { Initial titre }+ \text { Final titre }}
$$

For thermo-gravimetric analysis, a quantity of test sample was put into a pre-weighed crucible and the initial mass of the test sample at room temperature $\left(m_{o}\right)$ determined. The\% weight loss at temperature(s) of interest was evaluated by measuring the mass of the sample at these temperatures $\left(m_{T}\right)$ and then calculated using Equation (7).

$$
\operatorname{mass} \operatorname{loss} \%\left(\Delta m_{T} \%\right)=\frac{\left(m_{o}-m_{T}\right)}{m_{o} \times 100}
$$




\subsection{Preparation of Pectin Films}

The poly (vinyl alcohol) (PVA) was dissolved in an aqueous medium of $150 \mathrm{~mL}$ with vigorous and continuous stirring at a temperature range of $30^{\circ} \mathrm{C}$ to $95^{\circ} \mathrm{C}$ in a water bath in other to dissolve the PVA. This was followed with the addition of glycerol (0, 5 and $10 \mathrm{~mL}$ corresponding to Sample A, B and C) as the plasticizer and $1 \mathrm{~g}$ of pectin to each of the PVA/glycerol solution to form a pectin/glycerol/PVA blend. The film forming suspension was heated up with continuous mixing at $95^{\circ} \mathrm{C}$ for $10 \mathrm{~min}$ in a water bath. The plate was coated with a mould release agent and the blend was cast on the plate, such that a film was formed. The film was allowed to dry for 48 hours and then removed and sent for mechanical testing at Standard Organization of Nigeria (SON) Laboratory, Enugu, Nigeria. The tensile test was carried out according to ASTM 882-09 method [36].

\subsection{Results and Discussion}

The colour of extracted pectin by visual observation was brown/calabash colour. Pectin is usually light in colour [37]. The source and environmental factors could be responsible for this discrepancy in colour. The dry plantain pectin was found to be insoluble in cold and hot water, cold and hot alkali, $0.1 \mathrm{M}$ cold and hot $\mathrm{HCl}$, and is sparingly soluble in $0.2 \mathrm{M}$ cold and hot $\mathrm{HCl}$. However, the wet pectin was soluble in cold and hot water. This could be attributed to the presence and abundance of $-\mathrm{OH}$ groups in the wet pectin which is also present in water. The wet pectin suspension obtained on addition of $\mathrm{NaOH}$, gave a yellow gelatinous colour which turned white when heated at $85^{\circ} \mathrm{C}$ to $90^{\circ} \mathrm{C}$ for 15 minutes, this could be as a result of the depolymerization of the pectin [38] and is in agreement with an earlier report [34] which stated that pectin is unstable under alkaline solution.

The dry pectin was found to be sparingly soluble in $0.2 \mathrm{M} \mathrm{HCl}$. This could be as a result of the increased concentration level of the acid which corresponds to the conventional phenomenon which posits that pectin is soluble in acidic media but less soluble in alkaline media. The $\mathrm{pH}$ of the pectin was found to be 4.9 which is slightly acidic. The pectin yield and moisture content were found to be $40.5 \%$ and $87.56 \%$ respectively. This yield is interestingly higher than that reported for pectin extraction from citrus peel [39]. This therefore posits that pectin extracted from ripe plantain peel is among those with higher yields. However, results showed that pectin extracted from ripe plantain peel had lower moisture content of $87.56 \%$ than that from orange peel which gave $95.25 \%$ [40].

The equivalent weight $(\mathrm{g} / \mathrm{ml})$ is 1000 while the galacturonic acid contents are $2.89(\mathrm{mg} / \mathrm{mL})$. The degree of esterification was found to be $59.52 \%$. In accordance with standard practice for classification of commercial pectin, the pectin obtained in this work was categorized as high methoxyl pectin ( $D E \geq 50 \%$ ). Reference [21], studying the effects of ripeness stage of banana(Musa AAA) and plantain (Musa $\mathrm{AAB}$ ) peels reported higher pectin contents, galacturonic acid and methoxyl group contents at all the stages of maturation in banana peels 
compared to plantain peels, with average molecular weights of the extracted pectin ranging from 132.6 to $573.8 \mathrm{kDa}$, with pectin from banana peel being more highly esterified with degree of methylation (DM) ranging from $41.0 \%$ to $70.9 \%$ mol compared to that from plantain with DM ranging from $16 \%$ to $33 \%$ mol but similar degree of acetylation (DA) [21]. Figure 1 shows plates of pectin/ PVA/glycerol composite, dry pectin and the pectin film fabricated.

Direct comparison of the quantitative values for pectin from literature is challenging due to differences in extraction methods, the form of the starting material, and analysis method employed. This is exacerbated by the fact that these parameters, (pectin yield, equivalent weight, galacturonic acid content and DE) can be influenced by the extraction method/protocol employed. In spite of these challenges, in an attempt to give perspective on the chemical properties of the pectin extracted in this work a comparison with chemical properties of pectin extracted from other plant sources is presented in Table 1.

The mechanical properties tests carried out show that the properties of pectin-composite films obtained were enhanced with increase in glycerol volume. Tensile strength is influenced by intermolecular associations in the polymer matrix, which is often weakened by incorporation of a plasticizer, which works by spacing the chains of the polymer, allowing the chains to move more flexibly and thus making the plastics softer. Tensile strength values were $1.43,4.87$, and 5.51 MPa for films containing 0,5 , and $10 \mathrm{ml}$ glycerol respectively. This is higher than tensile strength values of amidated pectin with the highest tensile strength of $1.58 \mathrm{MPa}$ [41].
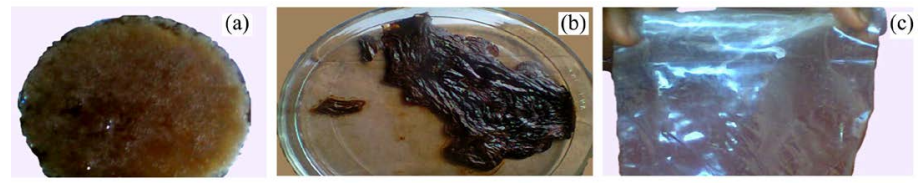

Figure 1. (a). Pectin/ poly (vinyl alcohol)/glycerol composite (b). Dry pectin (c). Plantain pectin film.

Table 1. Comparison of the chemical composition of pectin from different sources.

\begin{tabular}{|c|c|c|c|c|c|c|}
\hline Pectin source & $\begin{array}{l}\text { Equivalent/ } \\
\text { molecular wt. }\end{array}$ & pectin yield & $\begin{array}{l}\text { Galacturonic } \\
\text { acid content }\end{array}$ & $\begin{array}{l}\text { Degree of } \\
\text { methylation (DE) }\end{array}$ & $\begin{array}{l}\text { Moisture } \\
\text { content }\end{array}$ & Reference \\
\hline Plaintain & $1000 \mathrm{~g} / \mathrm{ml}$ & $40.5 \%$ & $2.89 \mathrm{mg} / \mathrm{ml}$ & $59.52 \%$. & $87.56 \%$ & This work \\
\hline Plaintain & $132.6-570.7 \mathrm{kDa}$ & $8.9-14.6^{* *}$ & $22.5-55.4^{*}$ & $14.2-30.6$ & - & [17] \\
\hline Banana & $252.8-573.5 \mathrm{kDa}$ & $10.3-21.7^{\star *}$ & $44.3-67.1^{*}$ & $35-67.1$ & - & [17] \\
\hline Grape & & $15.70^{\star \star *}$ & & $3.90 \%$ & $80.95 \%$ & [40] \\
\hline Orange & & $15.92^{\star * *}$ & & $5.79 \%$ & $95.25 \%$ & {$[40]$} \\
\hline Orange & & & & $29 \%-36 \%$ & & [40] \\
\hline Lemon & & $16.71^{\star * *}$ & & $4.46 \%$ & $66.60 \%$ & [40] \\
\hline Lemon & & & & $23 \%-46 \%$ & & [40] \\
\hline Citrus & & & $\geq 74.0 \%$ ** & $\geq 6.7 \%$ & & Sigma-Aldrich \\
\hline
\end{tabular}

${ }^{*}\left(\mathrm{GalA} / 100 \mathrm{~g}\right.$ of extract); ${ }^{* *}(\%$ of dry matter $) ;{ }^{* * *}(\%$ of wet matter $)$. 
The expectation that the addition of glycerol will result in improvements of the elasticity of the films was achieved, as film elongation values of $3.13,4.43$, and $5.75 \%$ were obtained for films containing 0,5 , and $10 \mathrm{ml}$ of glycerol respectively. The weight losses obtained for each of samples A, B and C were 1.0, 2.2 and $3.0 \mathrm{~g}$ respectively.

The compositions of the pectin composite films produced in this work are presented in Table 2.

Since from Table 2 it is obvious that PVA is a significant component of the Pectin/PVA/glycerol composite films obtained in this work, a comparison is made of the mechanical properties of our Pectin/PVA/glycerol composite films and reported values for PVA films in the literature. Poly (vinyl alcohol) is a water soluble polymer, containing multi hydroxyl groups, with the hydroxyl groups contributing to strong hydrogen bonding (both intra- and inter-molecularly), which confers PVA with such desirable properties as high tensile strength, excellent adhesive properties, abrasion resistance, anti-alkaline resistance and good gas barrier properties [42] [43] [44].

Reference [44] has demonstrated that the mechanical properties of PVA films are affected by the processing conditions, with tensile strength of drawn films increasing with increase in drawing temperature, and reported tensile strengths in the range of $57.4 \mathrm{MPa}$ (undrawn blown film) to $203 \mathrm{MPa}$ (blown films drawn at $120^{\circ} \mathrm{C}$ ), with the ductility of their PVA films ranging from $22.2 \%$ (for cross-linked films) to $24.6 \%$ (for uncross-linked films). Comparing the best mechanical properties of the Pectin/PVA/glycerol composite films obtained in this work; tensile strength and \% elongation of $5.51 \mathrm{MPa}$ and $5.75 \%$ respectively (obtained with $10 \mathrm{ml}$ glycerol/1g pectin), it is observed that these values though much lower than values for PVA films [44], is in the range of values reported by other authors.

Comparing values of mechanical properties for pectin composite films with reports for similar waste/agricultural products based films in the literature as shown in Table 3, it is concluded that the mechanical properties of the films obtained in this work were consistent with reported values for similar films. For a more robust comparison of the mechanical properties (tensile strength) of films based on materials sourced from fruits and vegetables, the recent review by [45] is recommended.

Reference [45] reported that the tensile strengths of edible films based on fruits and vegetables range in values as low as 0.03 up to $30 \mathrm{MPa}$. These values are comparable to the tensile strength values of some plastic films currently employed in food packaging, such as low-density PE (LDPE, 8 to $10 \mathrm{MPa}$ ), high-density PE (HDPE, 19 to $31 \mathrm{MPa}$ ), ethylene-vinyl alcohol copolymer (EVOH, 6 to $19 \mathrm{MPa}$ ) and PCL (4 MPa), but much smaller than those of polystyrene (PS, 31 to $49 \mathrm{MPa}$ ), poly (lactic acid) (PLA, $45 \mathrm{MPa}$ ), PVC (42 to 55 $\mathrm{MPa}$ ), PP (27 to $98 \mathrm{MPa}$ ) and poly(ethylene terephthalate) (PET, 157 to 177 $\mathrm{MPa}$ ). On the other hand, the reported ductility (\% elongation at breaking point) 
Table 2. Composition of pectin films (in parts per $100 \mathrm{~mL}$ of $\mathrm{H}_{2} \mathrm{O}$ ).

\begin{tabular}{ccccc}
\hline Sample & Glycerol (Pph) & PVA (Pph) & Pectin (Pph) & Water (Part) \\
\hline A & 0 & 27 & 0.67 & 100 \\
B & 3.3 & 27 & 0.67 & 100 \\
C & 6.7 & 27 & 0.67 & 100 \\
\hline
\end{tabular}

Table 3. Comparative table of reported mechanical properties of biofilms.

\begin{tabular}{llll}
\hline Film Composition & Tensile strength (MPa) & Elongation (\%) & References \\
\hline PVA/AP film (0\% to 30\% AP) & $11.24 \pm 1.27(0 \% \mathrm{AP})$ & $1.78 \pm 0.25$ & {$[46]$} \\
PVA/Pectin/Glycerol & $2.0 \pm 0.76(30 \% \mathrm{AP})$ & $0.88 \pm 0.28$ & \\
(10 mL glycerol/1g pectin) & $\approx 5.51$ & $\approx 5.75$ & This work \\
Low methoxyl pectin - Glycerol & 2.49 (at 0\% glycerol) & 13.24 & \\
(Gly) & 6.01 (at 20\% glycerol) & 17.56 & [47] \\
& 3.16 (at 40\% glycerol) & 32.75 & \\
Low methoxy pectin - Sorbitol (Sor) & 2.49 (at 0\% Sorbitol) & 13.24 & \\
& (at 40\% Sorbitol) & 22.3 & \\
Low methoxy pectin- propyl glycol & 2.49 (at 0\% PG) & 13.24 & \\
(PG) & $8.51($ at 20\% PG) & 18.80 & [47] \\
& 6.90 (at 40\% PG) & 27.25 & \\
Lowmethoxy pectin - polyethylene & 2.49 (at 0\% PEG) & 13.24 & \\
glycol (PEG) & 6.24 (at 20\% PEG) & 18.47 & [4] \\
& & 16.95 & \\
\hline
\end{tabular}

for these films based on the reviewed literature is in the range of $1.8 \%$ to $21.7 \%$, which was considered to be comparable to reported elongation values for PS ( $2 \%$ to $3 \%$ ), PVDC ( $10 \%$ to $40 \%), \operatorname{HDPE}(20 \%$ to $50 \%)$, PET (70\%), and PVC $(20 \%$ to $180 \%)$, but quite inferior to reported elongation values for PP $(200 \%$ to $1000 \%$ ), LDPE (300\% to $900 \%$ ), and PCL (800\% to 1000\%) [41] [47] [48].

The Raman spectra of pectin are shown in Figure 2. The Raman spectra of plantain peel showed a peak around $2930 \mathrm{~cm}^{-1}$ due to the $\mathrm{CH}$ - stretching modes of pectin. The peak at $1750 \mathrm{~cm}^{-1}$ is attributed to the carbonyl vibration band of acetyls $(\mathrm{C}=\mathrm{O})_{\mathrm{Ac}}$ due to ester group in pectin. The peak at $1430 \mathrm{~cm}^{-1}$ suggests the presence of COO- while the presence of aliphatic cyclic secondary alcohol is indicated by a peak at $1150 \mathrm{~cm}^{-1}$, (COC) glycosidic bond. The peak at $1100 \mathrm{~cm}^{-1}$ might correspond to the vibration mode of cellulose (COC). The band at 990 $1000 \mathrm{~cm}^{-1}$ could be assigned $-\mathrm{OCH}_{3}$ vibration of methyl esters [49].

\subsection{Differential Thermal Analysis}

The thermograms for pectin from plantain peel and citrus pectin showing the mass loss and DTA curves can be seen in Figure 3(a) and Figure 3(b). The differential scanning calorimetry (DSC) showed an endothermic melting process between $50^{\circ} \mathrm{C}$ and $80^{\circ} \mathrm{C}$. Similar observation was made by [34]. Figure 3(a) shows two degradative steps, the first one is due to film dehydration and it is at about $155^{\circ} \mathrm{C}$ while the second is attributable to decomposition of film. This is in agreement with reference [50]. Thermal analysis of the composite films indicates 
partial decomposition in a single stage between $220^{\circ} \mathrm{C}-270^{\circ} \mathrm{C}$ for plantain in Argon which is in line with that obtained for citrus pectin (Sigma) in Argon $\left(200^{\circ} \mathrm{C}-230^{\circ} \mathrm{C}\right)$. This observed thermal stability of plantain pectin compared to citrus pectin is tentatively attributed to differences in the chemical composition of both pectin (Table 1), especially differences in the galacturonic acid content and the degree of methylation. The much higher degree methylation of the pectin from plantain peel might be suggestive of a demand for more thermal energy for de-methylation process during thermal degradation. Another factor that might account for the better thermal stability of pectin from plantain peel might be a higher molecular weight range/distribution. However, this cannot be confirmed due to lack of information on the molecular weight ranges.
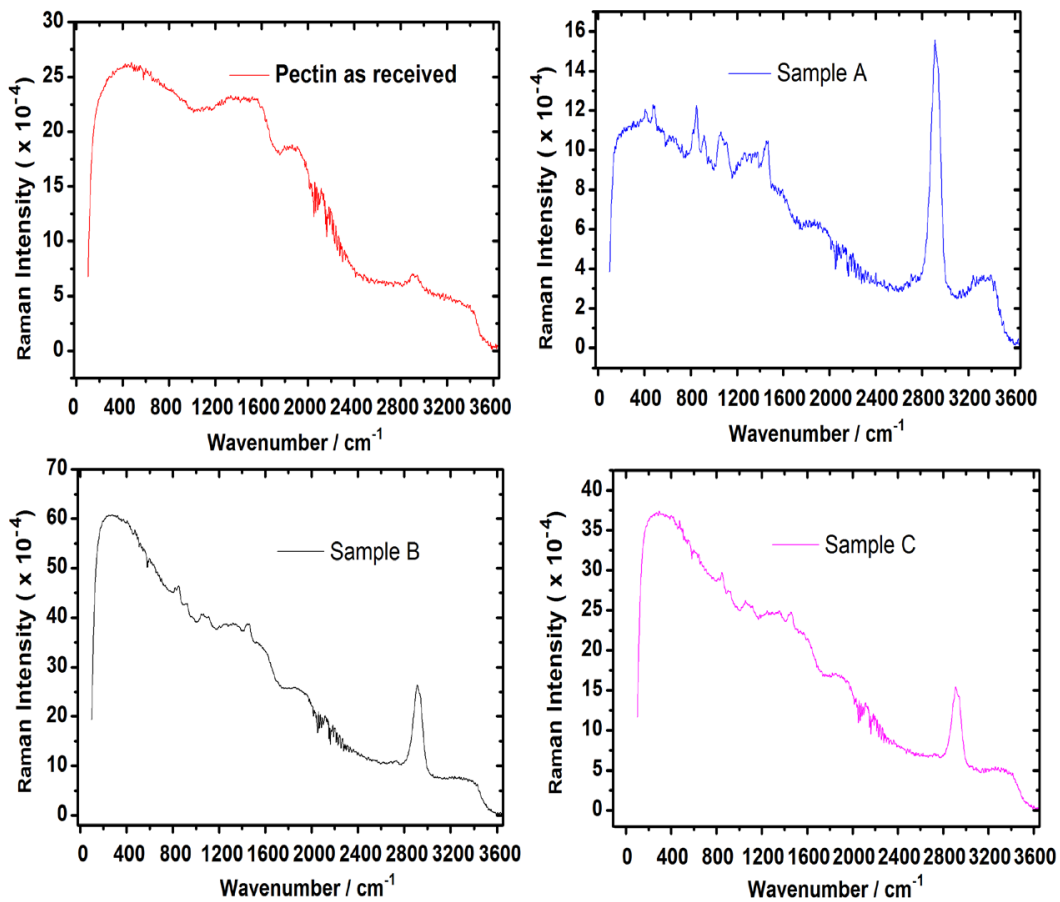

Figure 2. Raman Spectra of plantain pectin-PVA composite films with $0 \mathrm{~mL}$ glycerol (Sample A), $5 \mathrm{~mL}$ glycerol (Sample B), and $10 \mathrm{~mL}$ glycerol (Sample C).
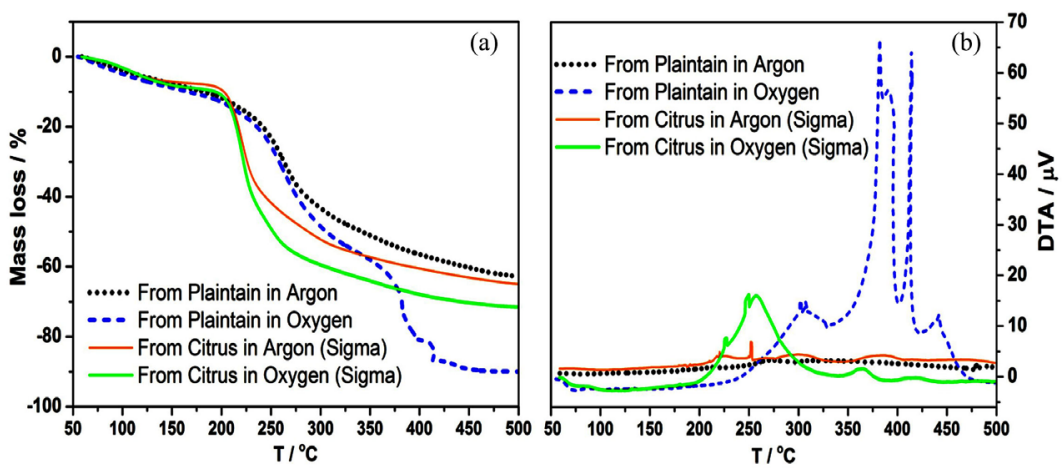

Figure 3. Comparison of the thermal degradation of pectin synthesized from plantain peel and that synthesized from citrus and sourced from Sigma in argon and oxygen respectively; (a) Mass loss curves, and (b) DTA curves. 


\section{Conclusion}

From the results obtained in this work, the percentage yield of pectin from ripe plantain peel is as high as $40.5 \%$. However, in accordance with standard for classifying commercial pectin, the pectin obtained in this work was categorized as high methoxyl pectin ( $\mathrm{DE}>50 \%$ ) which can also be a good cholesterol lowering agent. The use of glycerol as plasticizer was observed to lead to significant increase in the values of tensile strength and higher \% elongation in the films obtained. Tensile strength values were 1.43, 4.87, 5.51 MPa for films containing 0 , 5 , and $10 \mathrm{ml}$ glycerol respectively. The expected improvements in the elasticity of the films by addition of glycerol were achieved. With regards to films, \% elongation values of $3.13 \%, 4.43 \%, 5.75 \%$, were obtained for films containing 0 , 5 , and $10 \mathrm{ml}$ glycerol respectively. The use of Raman Spectroscopy enabled the analysis of the complex skeletal vibrations of the poly saccharide such as the glycosidic bonds, (COC, 1150 and $\mathrm{COH}, 480 \mathrm{~cm}^{-1}$ ) and pyranoid rings (673 $\mathrm{cm}^{-1}$ ). Since the PVA can be produced from non-fossil fuel sources, mobilization of pectin from waste products as a component of composite films with potential applications in the packaging industry as demonstrated in this work can be a plausible greener and renewable source of packaging materials in contrast to the current dependence on petroleum based sources and hence contribute to the emerging bio economy.

\section{Conflicts of Interest}

The authors declare no conflicts of interest regarding the publication of this paper.

\section{References}

[1] Mishra, R.K., Banthia, A.K. and Majeed, A.B.A. (2012) Pectin Based Formulations for Biomedical Application: A Review. Asian Journal of Pharmaceutical and Clinical Research, 5, 1-7.

[2] Graham, R.P. and Shepherd, A.D. (1953) Pectin Production, Pilot Plant Production of Low-Methoxyl Pectin from Citrus Peel. Journal of Agricultural and Food Chemistry, 1, 993-1001. https://doi.org/10.1021/jf60016a004

[3] Rouse, A.H. and Crandall, P.G. (1976) Nitric Acid Extraction of Pectin from Citrus Peel. Proceedings of the Florida State Horticultural Society, Vol. 89, 166-168.

[4] Rouse, A.H. and Crandall, P.G. (1978) Pectin Content of Lime and Lemon Peel as Extracted by Nitric Acid. Journal of Food Science, 43, 72-73. https://doi.org/10.1111/j.1365-2621.1978.tb09738.x

[5] Sakai, T. and Okushima, M. (1980) Microbial Production of Pectin from Citrus Peel. Applied and Environmental Microbiology, 39, 908-912.

[6] Donaghy, J.A. and. McKay, A.M. (1994) Pectin Extraction from Citrus Peel by Polygalacturonase Produced on Whey. Bioresource Technology, 47, 25-28. https://doi.org/10.1016/0960-8524(94)90024-8

[7] Pourbafrani, G., Forgács, Horváth, I.S., Niklasson, C. and Taherzadeh, M.J. (2010) Production of Biofuels, Limonene and Pectin from Citrus Wastes. Bioresource Technology, 101, 4246-4250. https://doi.org/10.1016/j.biortech.2010.01.077 
[8] Srirangarajan, A.N. and Shrikhande, A.J. (1977) Characterization of Mango Peel Pectin. Journal of Food Science, 42, 279-280. https://doi.org/10.1111/j.1365-2621.1977.tb01273.x

[9] Tafazzal, H., Baig, M.Q. and Haroon, R. (1991) Extraction and Evaluation of Pectin from Mango Peel. Pakistan Journal of Agricultural Research, 12, 213-216.

[10] Sudhakar, D.V. and Maini, S.B. (2000) Isolation and Characterization of Mango Peel Pectins. Journal of Food Processing and Preservation, 24, 209-227. https://doi.org/10.1111/j.1745-4549.2000.tb00414.x

[11] Berardini, N., Knödler, M., Schieber, A. and Carle, R. (2005) Utilization of Mango Peels as a Source of Pectin and Polyphenolics. Innovative Food Science \& Emerging Technologies, 6, 442-452. https://doi.org/10.1016/j.ifset.2005.06.004

[12] Banerjee, J., Vijayaraghavan, R., Arora, A., Macfarlane, D.R. and Patti, A.F. (2016) Lemon Juice Based Extraction of Pectin from Mango Peels: Waste to Wealth by Sustainable Approaches. ACS Sustainable Chemistry \& Engineering, 4, 5915-5920. https://doi.org/10.1021/acssuschemeng.6b01342

[13] Eda, S. and Katō, K. (1980) Pectin Isolated from the Midrib of Leaves of Nicotiana Tabacum. Agricultural and Biological Chemistry, 44, 2793-2801. https://doi.org/10.1271/bbb1961.44.2793

[14] Ning, H.F. and Tong, Q.Y. (2011) Study on Extraction of Pectin from Leaves of Premna microphylla Turcz in the Presence of Mixed Acids. Science and Technology of Food Industry, 1, 54.

[15] Ning, H.F. and Tong, H.F. (2011) Ultrasonic-Microwave Synergistic Extraction of Pectin from Leaves of Premna Microphylla Turez. Food Science and Technology, 3, 41.

[16] Emaga, T.H., Ronkart, S.N., Robert, C., Wathelet, B. and Paquot, M. (2008) Characterization of Pectins Extracted from Banana Peels (Musa AAA) under Different Conditions Using an Experimental Design. Food Chemistry, 108, 463-471. https://doi.org/10.1016/j.foodchem.2007.10.078

[17] Qiu, L.P., Zhao, G.L., Wu, H., Jiang, L., Li, X.F. and Liu, J.J. (2010) Investigation of Combined Effects of Independent Variables on Extraction of Pectin from Banana Peel Using Response Surface Methodology. Carbohydrate Polymers, 80, 326-331. https://doi.org/10.1016/j.carbpol.2010.01.018

[18] Oliveira, T.Í.S., et al. (2016) Optimization of Pectin Extraction from Banana Peels with Citric Acid by Using Response Surface Methodology. Food Chemistry, 198, 113-118. https://doi.org/10.1016/j.foodchem.2015.08.080

[19] Maneerat, N., Tangsuphoom, N. and Nitithamyong, A. (2017) Effect of Extraction Condition on Properties of Pectin from Banana Peels and Its Function as Fat Replacer in Salad Cream. Journal of Food Science and Technology, 54, 386-397. https://doi.org/10.1007/s13197-016-2475-6

[20] Khamsucharit, P., Laohaphatanalert, K., Gavinlertvatana, P., Sriroth, K. and Sangseethong, K. (2017) Characterization of Pectin Extracted from Banana Peels of Different Varieties. Food Science and Biotechnology, 27, 623-629.

https://doi.org/10.1007/s10068-017-0302-0

[21] Emaga, T.H., Robert, C., Ronkart, S.N., Wathelet, B. and Paquot, M. (2008) Dietary Fibre Components and Pectin Chemical Features of Peels during Ripening in Banana and Plantain Varieties. Bioresource Technology, 99, 4346-4354. https://doi.org/10.1016/j.biortech.2007.08.030

[22] Arun, K.B., et al. (2015) Plantain Peel-A Potential Source of Antioxidant Dietary Fibre for Developing Functional Cookies. Journal of Food Science and Technology, 
52, 6355-6364. https://doi.org/10.1007/s13197-015-1727-1

[23] Madhav, A. and Pushpalatha, P.B. (2006) Characterization of Pectin Extracted from Different Fruit Wastes. Journal of Tropical Agriculture, 40, 53-55.

[24] Thakur, B.R., Singh, R.K., Handa, A.K. and Rao, M.A. (1997) Chemistry and Uses of Pectin: A Review. Critical Reviews in Food Science \& Nutrition, 37, 47-73. https://doi.org/10.1080/10408399709527767

[25] Bhaskar, T., et al. (2016) Waste Biorefinery-Advocating Circular Economy. Bioresource Technology, 215, 1. https://doi.org/10.1016/j.biortech.2016.06.020

[26] Callaghan, K.O. (2016) Technologies for the Utilization of Biogenic Waste in the Bioeconomy. Food Chemistry, 198, 2-11. https://doi.org/10.1016/j.foodchem.2015.11.030

[27] Mohan, S.V., Butti, S.K., Amulya, K., Dahiya, S. and Modestra, J.A. (2016) Waste Biorefinery: A New Paradigm for a Sustainable Bioelectro Economy. Trends in Biotechnology, 34, 852-855. https://doi.org/10.1016/j.tibtech.2016.06.006

[28] Mohan, S.V., Nikhil, G.N., Chiranjeevi, P., Reddy, C.N., Rohit, M.V., Kumar, A.N. and Sarkar, O. (2016) Waste Biorefinery Models towards Sustainable Circular Bioeconomy: Critical Review and Future Perspectives. Bioresource Technology, 215, 2-12. https://doi.org/10.1016/j.biortech.2016.03.130

[29] Khanle, N., et al. (2015) Fruit Waste Streams in South Africa and Their Potential Role in Developing a Bio-Economy. South African Journal of Science, 111, 1-11.

[30] Schmidt, O., Padel, S. and Levidow, L. (2012) The Bio-Economy Concept and Knowledge Base in a Public Goods and Farmer Perspective. Bio-Based and Applied Economics, 1, 47-63.

[31] Fishman, M.L., Coffin, D.R., Konstance, R.P. and Onwulata, C.I. (2000) Extrusion of Pectin/Starch Blends Plasticized with Glycerol. Carbohydrate Polymers, 41, 317-325. https://doi.org/10.1016/S0144-8617(99)00117-4

[32] Galus, S. and Lenart, A. (2013) Development and Characterization of Composite Edible Films Based on Sodium Alginate and Pectin. Journal of Food Engineering, 115, 459-465. https://doi.org/10.1016/j.jfoodeng.2012.03.006

[33] Hoagland, P.D. and Parris, N.J. (1996) Chitosan/Pectin/Amidated Films. Journal of Agricultural and Food Chemistry, 44, 1915-1919. https://doi.org/10.1021/jf950162s

[34] Appelquist, I.A.M., Cooke, D., Gidley, M.J. and. Lane, S.J. (1993) Effect of Heat Treatment on the Pectins of Tomatoes during Tomato Paste Manufacturing. Carbohydrate Polymers, 20, 291-299.

[35] FCC V. (2004) Food Chemical Codex. National Academy of Science, Washington DC, 322-323.

[36] ASTM 882-09 (1995) Standard Test Method For Tensile Properties of Thin Plastic Sheeting. American Society for Testing Materials, West Conshohocken.

[37] International Pectin Producers Association IPPA (2009) http://www.interscience.com

[38] Catoir, L., Goldberg, R., Pierron, M., Morian, C. and Herve du Pen Boat, C. (1998) An Efficient Procedure for Studying Pectin Structure Which Combines Limited Depolymerization and 13C NMR. European Biophysics Journal, 27, 127-136. https://doi.org/10.1007/s002490050118

[39] Aina, V.O., et al. (2012) Extraction and Characterization of Pectin from Peels of Lemon (Citrus limon), Grape Fruit (Citrus paradis) and Sweet Orange (Citrus sinensis). British Journal of Pharmacology and Toxicology, 3, 259-262.

[40] Fidalgo, A., et al. (2016) Eco-Friendly Extraction of Pectin and Essential Oils from 
Orange and Lemon Peels. ACS Sustainable Chemistry \& Engineering, 44, 2243-2251. https://doi.org/10.1021/acssuschemeng.5b01716

[41] Mishra, R.K., Aniis, A., Mondal, S., Dutt, S. and Banthia, A.K. (2011) Reparation and Characterization of Amidated Pectin Based Polymer Electrolyte Membranes. Chinese Journal of Polymer Science, 27, 639-646. https://doi.org/10.1142/S0256767909004333

[42] Yan, R. (1940) Water Soluble Polymers. Chemical Industry Publisher, Beijing, 42.

[43] Sakurada, I. (1985) Polyvinyl Alcohol Fibers. Marcel Dekker, Inc., New York.

[44] Chen, L.N., Li, L. and Wang, Q. (2007) New Technology for Thermal Processing of Poly(vinyl alcohol). Plastics, Rubber and Composites, 36, 283-290. https://doi.org/10.1179/174328907X237575

[45] Otoni, C.G., et al. (2017) Recent Advances on Edible Films Based on Fruits and Vegetables: A Review. Comprehensive Reviews in Food Science and Food Safety, 16, 1151-1169. https://doi.org/10.1111/1541-4337.12281

[46] Gaikwad, K.K., Lee, J.Y. and Lee, Y.S. (2016) Development of Polyvinyl Alcohol and Apple Pomace Bio-Composite Film with Antioxidant Properties for Active Food Packaging Application. Journal of Food Science and Technology, 53, 1608-1619. https://doi.org/10.1007/s13197-015-2104-9

[47] Jantrawut, P., Chaiwarit, T., Jantanasakulwong, K., Brachais, C.H. and Chambin, O. (2017) Effect of Plasticizer Type on Tensile Property and in Vitro Indomethacin Release of Thin Films Based on Low-Methoxyl Pectin. Polymers, 9, 289. https://doi.org/10.3390/polym9070289

[48] Bastarrachea, L., Dhawan, S. and Sablani, S.S. (2011) Engineering Properties of Polymeric-Based Antimicrobial Films for Food Packaging: A Review. Food Engineering Reviews, 3, 79-93. https://doi.org/10.1007/s12393-011-9034-8

[49] Synytsya, A., Copikova, J., Matejka, P. and Machovic, V. (2003) Fourier Transform Raman and Infrared Spectroscopy of Pectins. Carbohydrate Polymers, 54, 97-106. https://doi.org/10.1016/S0144-8617(03)00158-9

[50] Siracusa, V., et al. (2018) Characterization of Active Edible Films Based on Citral Essential Oil, Alginate and Pectin. Materials, 11, pii: E1980.

https://doi.org/10.3390/ma11101980 